\title{
Control of Radiation Sensitivity of the Oxygen-Containing Fluorite Crystals
}

\author{
S.I. KAChAN ${ }^{a, *}$, V.M. SAlAPAK ${ }^{b}$, O.A. NAHURSKIY ${ }^{a}$ AND I.B. PiRKO ${ }^{b}$ \\ ${ }^{a}$ Lviv Polytechnic National University, 12 Bandera Str., 79013 Lviv, 79013, Ukraine \\ ${ }^{b}$ Ukrainian National Forestry University, 103 Gen. Chuprynky Str., Lviv, 79057, Ukraine
}

\begin{abstract}
The parameters of radiation sensitivity of the oxygen-doped fluorite crystals were calculated in a onedimensional model. The limit concentrations of the color centers as a function of the concentration of the oxygen impurity in the fluorite crystal were defined. Fluorite crystals with anti-Frenkel defects in the anion sublattice of the crystal have a specific property: the discolored after irradiation crystal being irradiated repeatedly with ionizing radiation retains the "memory" of the preceding irradiation. Using an ion chain model this paper studies under what conditions the "radiation memory" effect can arise in the $\mathrm{MeF}_{2}-\mathrm{O}^{2-}$ crystals as well as the extent of its contribution into the overall radiation sensitivity of the crystal.
\end{abstract}

DOI: 10.12693/APhysPolA.133.824

PACS/topics: 61.80.--x, 78.47.-p, 78.70.--g

\section{Introduction}

Fluorite crystals have found a widespread use in photolithography, laser technology, dosimetry, as well as model objects for theoretical research of ionic crystals. As it is known from [1], "pure" crystals do not get colored under irradiation, i.e. they are radiation-resistant. If the fluorites are doped with non-isovalent impurities (alkali metal ions or oxygen ions), then host ions get substituted by impurity ions and vacancies arise in the immediate surrounding forming impurity-vacancy dipoles (IVD).

If the fluorite crystals with such defects get irradiated, color centers appear whose properties are used in practice. They have differing structure at different temperature [1]. For practical application, one has to achieve the maximum concentration of color centers or, in other terms, achieve the maximum radiation sensitivity of the crystal. But this cannot be accomplished only by increasing the concentration of the doping impurity. The common approach to do it is modifying crystals using irradiation, heating, and illumination. But it is necessary to determine the execution sequence basing on the previous experimental results and theoretical calculations of the following actions: irradiation at nitrogen temperatures, heating to room temperature, cooling to liquid nitrogen temperature, photo-bleaching of the crystal at this temperature, re-irradiation. These procedures cause practically a substantial increase in radiation sensitivity of doped fluorites. The objective of this study consists in the enhancement of the radiation sensitivity (enhancement of the limit concentration of color centers) in the fluorite-structured doped crystals by creating in the lattice of the thermally non-equilibrium structural defects. In order to explain the efficiency of the proposed modifi-

*corresponding author; e-mail: sikach@gmail.com cation, we calculate the color centers concentrations and their changes under various ways of the crystal treatments using the ion chain model.

Because ionic radii of the fluorine and oxygen are almost identical in size and are equal to 1.33 and $1.36 \AA$, accordingly, the oxygen ions easily enter into the fluorites' crystal matrix and both synthetic and natural crystals contain more or less oxygen impurity. Presence of the oxygen as a background impurity worsens the optical transparency of the fluorites in the ultraviolet spectral region and reduces their radiation resistance.

The current paper is structured as follows: it starts by summarizing experimental results, the information on defects structure in $\mathrm{MeF}_{2}-\mathrm{O}^{2-}$ crystals, as well as the color centers formation mechanism under the influence of ionizing radiation. Based on the experimental results, radiation sensitivity of the $\mathrm{MeF}_{2}-\mathrm{O}^{2-}$ crystals is calculated in an ion chain model further. Finally, the obtained results are discussed and conclusions are made.

\section{Point defects structure in the $\mathrm{MeF}_{2}-\mathrm{O}^{2-}$ crystals before and after their irradiation at different temperatures}

$\mathrm{CaF}_{2}-\mathrm{O}^{2-}$ and $\mathrm{SrF}_{2}-\mathrm{O}^{2-}$ crystals were grown in an inert atmosphere in the graphite ampoules by the modified Bridgman technique. The crystals were doped with oxygen by adding $\mathrm{CaCO}_{3}$ or $\mathrm{SrCO}_{3}$ salts to the charge. The entry of oxygen into the crystal as well as its concentration was monitored by measurements of IVD relaxation currents. Investigated samples were in the form of plates cut out in the plane (110) or (100) of the crystal (cleavage plane is (110)). The irradiation conditions of the samples, the measurement techniques of the induced absorption spectra and the thermo-stimulated depolarization currents (TSDC) were described in our previous paper [2].

As it follows from data on the ionic conductivity study of the $\mathrm{MeF}_{2}-\mathrm{O}^{2-}$ crystals [3], theoretical investi- 
gation [4], as well as from own studies of TSDC [2, 5] and defects induced by electron pulse irradiation [6], $\mathrm{O}^{2-}$-ions enter into the lattice of fluorite crystals substituting the host ions. Electric charge of the impurity ion is surplus relative to the lattice and is compensated by the anionic vacancy. On the base on known data one can state that the following defects can be formed in $\mathrm{MeF}_{2}-\mathrm{O}^{2-}$ crystals:

$$
\begin{aligned}
& \ominus \quad \text { the substituting ion } \mathrm{O}^{2-}\left(\mathrm{O}_{\mathrm{F}^{-}}^{2-}\right)^{\prime} \text {; } \\
& \boxplus \quad \text { the fluorine vacancy }\left(V_{\mathrm{F}^{-}}\right)^{\bullet} \text {; } \\
& \ominus \boxplus \quad \text { impurity-vacancy dipole (IVD) }\left[\left(\mathrm{O}_{\mathrm{F}^{-}}^{2-}\right)^{\prime}\left(V_{\mathrm{F}^{-}}\right)^{\bullet}\right]^{x} \text {; } \\
& \square \quad \text { F-center }\left[\left(V_{\mathrm{F}^{-}}\right)^{\bullet} e^{-}\right]^{x} \text {; } \\
& \ominus \square \quad \mathrm{F}_{A^{-}} \text {-center }\left[\left(V_{\mathrm{F}^{-}}\right)^{\bullet} e^{\left.-\left(\mathrm{O}_{\mathrm{F}^{-}}^{2-}\right)^{\prime}\right]^{\prime} ;}\right. \\
& \bigcirc \quad \text { the substituting ion } \mathrm{O}^{-}\left[\mathrm{O}_{\mathrm{F}^{-}}^{-}\right]^{x} \text {; } \\
& \bigcirc \mathrm{O}^{-}(1) \text {-center }\left[\left(\mathrm{O}_{\mathrm{F}^{-}}^{-}\right)^{x}\left(\mathrm{~V}_{\mathrm{F}^{-}}\right)^{\bullet}\right]^{\bullet} \text {; }
\end{aligned}
$$

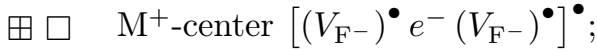

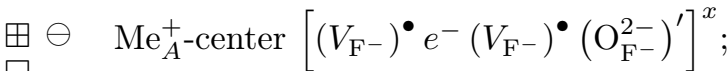

$\boxplus \ominus \square \mathrm{F}_{D^{-}}$-center (F-center located near IVD).

$$
\left[\left(V_{\mathrm{F}^{-}}\right)^{\bullet} e^{-}\left(\mathrm{O}_{\mathrm{F}^{-}}^{2-}\right)^{\prime}\left(V_{\mathrm{F}^{-}}\right)^{\bullet}\right]^{x}
$$

Color centers models are shown schematically in Fig. 1.

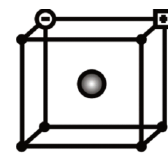

IVD

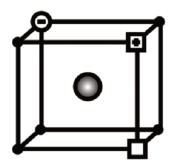

$\mathrm{M}_{\mathrm{A}}^{+}$

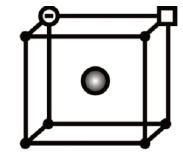

$\mathrm{F}_{\mathrm{A}}$

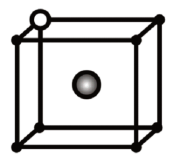

$\mathrm{O}^{-}$

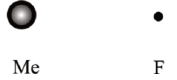

○

\section{口.}

口 $\quad 0$

Fig. 1. IVD and color centers models in the $\mathrm{MeF}_{2}-\mathrm{O}^{2-}$ crystals.

As is known from experimental data on thermally stimulated depolarization currents [2], at $T<150 \mathrm{~K}$ anionic vacancies are "frozen" in the crystal lattice. At the temperature $>150 \mathrm{~K}$ anionic vacancies are located in the vicinity of an oxygen ion (forming the IVD) and are able to perform only rotational motion in the vicinity of an impurity. Temperature dependences of the dipole relaxation conductivity of the $\mathrm{MeF}_{2}-\mathrm{O}^{2-}$ crystal are presented in Fig. 2.

Impurity-vacancy dipoles being the growth defects can be manifested in the studies of the TSD currents. If the doped crystals are being irradiated at differing temperatures, different color centers emerge: at low-temperature irradiation, these are $\mathrm{F}_{A}$-centers, at room temperatures

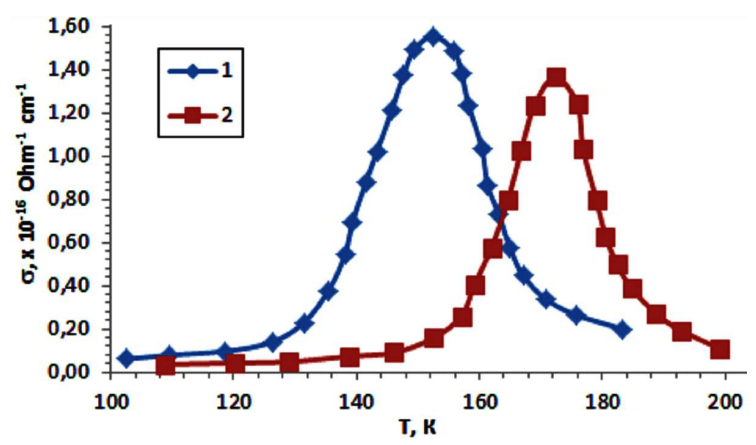

Fig. 2. Temperature dependence of the dipole relaxation conductivity (thermally stimulated depolarization currents) of $\mathrm{CaF}_{2}-\mathrm{O}^{2-}$ (1) and $\mathrm{SrF}_{2}-\mathrm{O}^{2-}$ (2) crystals at polarization electric field strength $E_{p}=5000 \mathrm{~V} / \mathrm{cm}$ and heating rate $\beta=0.1 \mathrm{~K} / \mathrm{s}$.

- $M_{A}^{+}$-centers. We fix them by means of absorption methods.

Color centers generation in the $\mathrm{MeF}_{2}-\mathrm{O}^{2-}$ crystals under low-temperature irradiation of the samples occurs by means of localization of the charge carriers on IVD:

$$
\begin{aligned}
& {\left[\left(\mathrm{O}_{\mathrm{F}^{-}}^{2-}\right)^{\prime}\left(V_{\mathrm{F}^{-}}\right)^{\bullet}\right]^{x} R\left(e^{-}, h^{+}\right)\left[\left(\mathrm{O}_{\mathrm{F}^{-}}^{2-}\right)^{\prime}\left(V_{\mathrm{F}^{-}}\right)^{\bullet}\right]^{x} \underset{\omega_{2}}{\stackrel{\omega_{1}}{\leftrightarrows}}} \\
& {\left[\left(V_{\mathrm{F}^{-}}\right)^{\bullet} e^{-}\left(\mathrm{O}_{\mathrm{F}^{-}}^{2-}\right)^{\prime}\right]^{\prime} R\left(e^{-}{ }^{+} h^{+}\right)\left[\left(\mathrm{O}_{\mathrm{F}^{-}}^{-}\right)^{x}\left(V_{\mathrm{F}^{-}}\right)^{\bullet}\right]^{\bullet}}
\end{aligned}
$$

$R\left(e^{-}, h^{+}\right)$is in this notation an electron-hole pair $\left(e^{-}, h^{+}\right.$generated by ionizing radiation $R ; \omega_{1}$ is a probability of capture of the charge carriers $\left(e^{-}, h^{+}\right)$ by the IVD-pair and, accordingly, of the emergence of the $\left\{\left[\left(V_{\mathrm{F}^{-}}\right)^{\bullet} e^{-}\left(\mathrm{O}_{\mathrm{F}^{-}}^{2-}\right)^{\prime}\right]^{\prime}-\left[\left(\mathrm{O}_{\mathrm{F}^{-}}^{-}\right)^{x}\left(V_{\mathrm{F}^{-}}\right)^{\bullet}\right]^{\bullet}\right\}$-pair of color centers; $\omega_{2}$ is a probability of destruction of $\left\{\left[\left(V_{\mathrm{F}^{-}}\right)^{\bullet} e^{-}\left(\mathrm{O}_{\mathrm{F}^{-}}^{2-}\right)^{\prime}\right]^{\prime}-\left[\left(\mathrm{O}_{\mathrm{F}^{-}}^{-}\right)^{x}\left(V_{\mathrm{F}^{-}}\right)^{\bullet}\right]^{\bullet}\right\}$-pair due to localization of the charge carriers $\left(e^{-}, h^{+}\right)$on the color centers and, accordingly, of the IVD-pair regeneration.

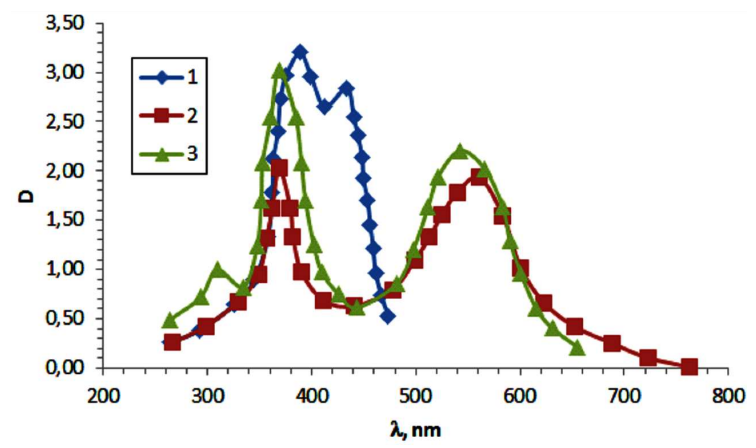

Fig. 3. Induced absorbance spectra of the irradiated $\mathrm{CaF}_{2}-\mathrm{O}^{2-}$ crystals irradiated at different temperatures: absorption of $\mathrm{F}_{A}$-centers formed by irradiation at $80 \mathrm{~K}$ (1) and absorption of $M_{A}^{+}$-centers induced by irradiation at $215 \mathrm{~K}(2)$ and $268 \mathrm{~K}(3)$. 


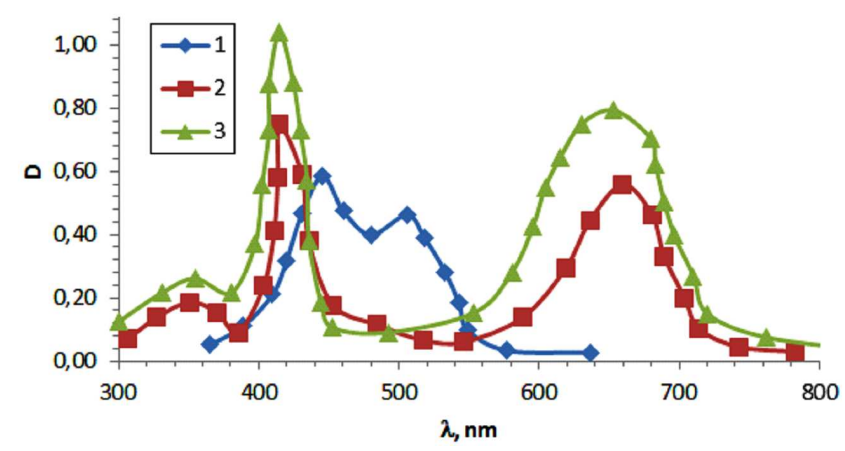

Fig. 4. Induced absorbance spectra of the $\mathrm{SrF}_{2}-\mathrm{O}^{2-}$ crystals irradiated at different temperatures: absorption

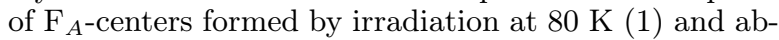
sorption of $M_{A}^{+}$-centers induced by irradiation at $215 \mathrm{~K}$ (2) and $268 \mathrm{~K}(3)$.

Figures 3 and 4 show induced absorbance spectra of $\mathrm{CaF}_{2}-\mathrm{O}^{2-}$ and $\mathrm{SrF}_{2}-\mathrm{O}^{2-}$ crystals irradiated by $\mathrm{X}$-rays at different temperatures. These spectra contain the same absorption bands of color centers.

According to Eq. (1), radiation destruction of each of the dipole pairs is accompanied by the emergence of $\left\{\left[\left(V_{\mathrm{F}^{-}}\right)^{\bullet} e^{-}\left(\mathrm{O}_{\mathrm{F}^{-}}^{2-}\right)^{\prime}\right]^{\prime}-\left[\left(\mathrm{O}_{\mathrm{F}^{-}}^{-}\right)^{x}\left(V_{\mathrm{F}^{-}}\right)^{\bullet}\right]^{\bullet}\right\}$ color centers pair. And vice versa, at radiation bleaching of $\left\{\left[\left(V_{\mathrm{F}^{-}}\right)^{\bullet} e^{-}\left(\mathrm{O}_{\mathrm{F}^{-}}^{2-}\right)^{\prime}\right]^{\prime}-\left[\left(\mathrm{O}_{\mathrm{F}^{-}}^{-}\right)^{x}\left(V_{\mathrm{F}^{-}}\right)^{\bullet}\right]^{\bullet}\right\}$-pair results in reconstruction of an IVD-pair.

IVD is electrically neutral associate relative to the lattice, $\left[\left(V_{\mathrm{F}^{-}}\right)^{\bullet} e^{-}\left(\mathrm{O}_{\mathrm{F}^{-}}^{2-}\right)^{\prime}\right]^{\prime}$ and $\left[\left(\mathrm{O}_{\mathrm{F}^{-}}^{-}\right)^{x}\left(V_{\mathrm{F}^{-}}\right)^{\bullet}\right]^{\bullet}$ centers - electrically charged relative to the lattice. The emergence of each of the color centers pairs disturbs the thermodynamic equilibrium of the crystal lattice and increases the potential energy of the lattice by about $1 \mathrm{eV}$ in colored crystals containing $\left\{\left[\left(V_{\mathrm{F}^{-}}\right)^{\bullet} e^{-}\left(\mathrm{O}_{\mathrm{F}^{-}}^{2-}\right)^{\prime}\right]^{\prime}-\left[\left(\mathrm{O}_{\mathrm{F}^{-}}^{-}\right)^{x}\left(V_{\mathrm{F}^{-}}\right)^{\bullet}\right]^{\bullet}\right\}$-pairs of color centers can be restored by heating of the crystal:

$$
\begin{gathered}
{\left[\left(\mathrm{O}_{\mathrm{F}^{-}}^{-}\right)^{x}\left(V_{\mathrm{F}^{-}}\right)^{\bullet}\right]^{\bullet} \cdots\left[\left(V_{\mathrm{F}^{-}}\right)^{\bullet} e^{-}\left(\mathrm{O}_{\mathrm{F}^{-}}^{2-}\right)^{\prime}\right]^{\prime} \underset{k T}{\stackrel{T>150}{\longrightarrow} \mathrm{K}}} \\
{\left[\mathrm{O}_{\mathrm{F}^{-}}^{-}\right]^{x} \cdots\left[\left(V_{\mathrm{F}^{-}}\right)^{\bullet} e^{-}\left(V_{\mathrm{F}^{-}}\right)^{\bullet}\left(\mathrm{O}_{\mathrm{F}^{-}}^{2-}\right)^{\prime}\right]^{x} .}
\end{gathered}
$$

Newly created $\left\{\left[\left(V_{\mathrm{F}^{-}}\right)^{\bullet} e^{-}\left(V_{\mathrm{F}^{-}}\right)^{\bullet}\left(\mathrm{O}_{\mathrm{F}^{-}}^{2-}\right)^{\prime}\right]^{x}-\left(\mathrm{O}_{\mathrm{F}^{-}}^{-}\right)^{x}\right\}-$ pairs of color centers are electrically neutral relative to the lattice, hence, they minimize the potential energy of the crystal lattice.

Experimental findings indicate that $\left\{\left[\left(V_{\mathrm{F}^{-}}\right)^{\bullet} e^{-}\left(V_{\mathrm{F}^{-}}\right)^{\bullet}\left(\mathrm{O}_{\mathrm{F}^{-}}^{2-}\right)^{\prime}\right]^{x}-\left(\mathrm{O}_{\mathrm{F}^{-}}^{-}\right)^{x}\right\}$-pairs of color centers can be generated in the crystal directly during irradiation while the samples are irradiated at $>150 \mathrm{~K}$ :

$$
\begin{gathered}
{\left[\left(\mathrm{O}_{\mathrm{F}^{-}}^{2-}\right)^{\prime}\left(V_{\mathrm{F}^{-}}\right)^{\bullet}\right]^{x} \begin{array}{c}
R\left(e^{-}, h^{+}\right) \\
T>150 \mathrm{~K}
\end{array}\left[\left(\mathrm{O}_{\mathrm{F}^{-}}^{2-}\right)^{\prime}\left(V_{\mathrm{F}^{-}}\right)^{\bullet}\right]^{x} \underset{\omega_{3}}{\stackrel{\omega_{4}}{\leftrightarrows}}} \\
{\left[\left(V_{\mathrm{F}^{-}}\right)^{\bullet} e^{-}\left(V_{\mathrm{F}^{-}}\right)^{\bullet}\left(\mathrm{O}_{\mathrm{F}^{-}}^{2-}\right)^{\prime}\right]^{x} \begin{array}{l}
R\left(e^{-}, h^{+}\right) \\
T>150 \mathrm{~K}
\end{array}\left[\mathrm{O}_{\mathrm{F}^{-}}^{-}\right]^{x} .}
\end{gathered}
$$

Here $\omega_{3}$ is probability of radiation bleaching of $\left\{\left[\left(V_{\mathrm{F}^{-}}\right)^{\bullet} e^{-}\left(V_{\mathrm{F}^{-}}\right)^{\bullet}\left(\mathrm{O}_{\mathrm{F}^{-}}^{2-}\right)^{\prime}\right]^{x}-\left(\mathrm{O}_{\mathrm{F}^{-}}^{-}\right)^{x}\right\}$-pair of color centers during the disintegration of the electron-hole pair in the ion chain.

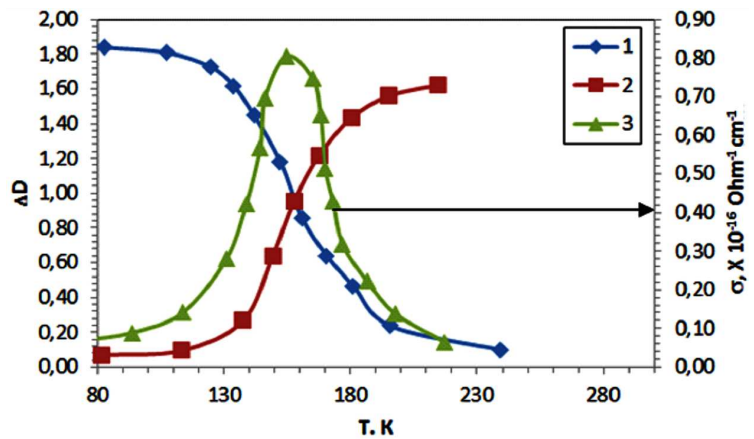

Fig. 5. The general picture of thermally stimulated processes during the heating of $\mathrm{CaF}_{2}-\mathrm{O}^{2-}$ crystals irradiated at $80 \mathrm{E}$ : thermal bleaching of $\mathrm{F}_{A}$-centers (1); the $\mathrm{M}_{A}^{+}$-centers formation (2) and the dipole relaxation conductivity (3) (thermally stimulated depolarization current) at polarization electric field strength $E_{p}=5000 \mathrm{~V} / \mathrm{cm}$ and heating rate $\beta=0.1 \mathrm{~K} / \mathrm{s}$.

The general picture of thermally stimulated processes during the heating of $\mathrm{CaF}_{2}-\mathrm{O}^{2-}$ crystals irradiated at $80 \mathrm{~K}$ is adduced in Fig. 5.

\section{Calculations of radiation sensitivity of crystals under re-irradiation}

Colored crystals containing

$\left\{\left[\left(V_{\mathrm{F}^{-}}\right)^{\bullet} e^{-}\left(V_{\mathrm{F}^{-}}\right)^{\bullet}\left(\mathrm{O}_{\mathrm{F}^{-}}^{2-}\right)^{\prime}\right]^{x}-\left(\mathrm{O}_{\mathrm{F}^{-}}^{-}\right)^{x}\right\}$-pairs

of color centers can be optically discolored by irradiating them with monochromatic light in $\left[\left(V_{\mathrm{F}^{-}}\right)^{\bullet} e^{-}\left(V_{\mathrm{F}^{-}}\right)^{\bullet}\left(\mathrm{O}_{\mathrm{F}^{-}}^{2-}\right)^{\prime}\right]^{x}$-absorption bands.

If the crystal is being discolored at $<150 \mathrm{~K}$, color centers bleaching leads to the emergence of new defects in the crystal lattice

$$
\begin{gathered}
{\left[\left(V_{\mathrm{F}^{-}}\right)^{\bullet} e^{-}\left(V_{\mathrm{F}^{-}}\right)^{\bullet}\left(\mathrm{O}_{\mathrm{F}^{-}}^{2-}\right)^{\prime}\right]^{x} \cdots\left[\mathrm{O}_{\mathrm{F}^{-}}^{-}\right]^{x} \underset{T<150 \mathrm{~K}}{\stackrel{h \nu}{\longrightarrow}}} \\
{\left[\left(V_{\mathrm{F}^{-}}\right)^{\bullet} e^{-}\left(\mathrm{O}_{\mathrm{F}^{-}}^{2-}\right)^{\prime}\left(V_{\mathrm{F}^{-}}\right)^{\bullet}\right]^{x} \cdots\left(\mathrm{O}_{\mathrm{F}^{-}}^{2-}\right)^{\prime} .}
\end{gathered}
$$

Thus, by means of photobleaching one can create new uncharacteristic structural defects in the crystal; this affects crystal physical properties, and in the first place, it changes their radiation sensitivity.

In the discolored crystals, there are both dipole-type defects inherent in synthetic crystals and charged defects thermally unbalanced non-equilibrium with the crystal lattice. Because of this, under low-temperature irradiation, besides reactions described by Eqs. (1), there are processes running in parallel leading to the emergence of the structurally novel color centers in the crystal

$$
\left(\mathrm{O}_{\mathrm{F}^{-}}^{2-}\right)^{\prime} \stackrel{R\left(e^{-}, h^{+}\right)}{\cdots}\left[\left(V_{\mathrm{F}^{-}}\right)^{\bullet} e^{-}\left(\mathrm{O}_{\mathrm{F}^{-}}^{2-}\right)^{\prime}\left(V_{\mathrm{F}^{-}}\right)^{\bullet}\right]^{x \underset{\omega_{6}}{\stackrel{\omega_{4}}{\leftrightarrows}}}
$$




$$
\left[\mathrm{O}_{\mathrm{F}^{-}}^{-}\right]^{x R\left(e^{-}, h^{+}\right)}\left[\left(V_{\mathrm{F}^{-}}\right)^{\bullet} e^{-}\left(\mathrm{O}_{\mathrm{F}^{-}}^{2-}\right)^{\prime}\left(V_{\mathrm{F}^{-}}\right)^{\bullet}\right]^{x},
$$

where $\omega_{4}$ is a probability of generation of $\left\{\left[\left(V_{\mathrm{F}^{-}}\right)^{\bullet} e^{-}\left(\mathrm{O}_{\mathrm{F}^{-}}^{2-}\right)^{\prime}\left(V_{\mathrm{F}^{-}}\right)^{\bullet}\right]^{x}-\left(\mathrm{O}_{\mathrm{F}^{-}}^{-}\right)^{x}\right\}-$ pair

of color centers during the dissolution of electronhole pair; $\omega_{5}$ is probability of bleaching of $\left\{\left[\left(V_{\mathrm{F}^{-}}\right)^{\bullet} e^{-}\left(\mathrm{O}_{\mathrm{F}^{-}}^{2-}\right)^{\prime}\left(V_{\mathrm{F}^{-}}\right)^{\bullet}\right]^{x}-\left(\mathrm{O}_{\mathrm{F}^{-}}^{-}\right)^{x}\right\}$-pair of color centers during the decay of electron-hole pair $\left(\omega_{5}=\omega_{2}\right)$.

Resulting from (5), the $\left\{\left[\left(V_{\mathrm{F}^{-}}\right)^{\bullet} e^{-}\left(\mathrm{O}_{\mathrm{F}^{-}}^{2-}\right)^{\prime}\left(V_{\mathrm{F}^{-}}\right)^{\bullet}\right]^{x}-\left(\mathrm{O}_{\mathrm{F}^{-}}^{-}\right)^{x}\right\}$-pairs of color centers emerge additionally in the crystal which increases the crystal radiation sensitivity.

In a one-dimensional model the real crystal can be presented in the form of an ion chain containing host ions and IVDs. Hence the calculations of radiation sensitivity of the crystals under initial and repeat ionizing irradiation can be fulfilled based on this model and assuming the following.

Under ionizing radiation, high-energy excitations arise in the ion chain, their decay into electron-hole pair occurs as a result of an electron escaping host anions. Emergent electron-hole pair can arise with equal probability in any of nodes of the ion chain while the distance between an electron and a hole varies depending on the electron excitation energy. The hole location during the escape of the electron remains unchanged which is determined by the large effective mass of the hole. Depending on the topological disposition of the electron, the hole, and the IVDs which limit the ion chain, the electron and the hole can form a pair of color centers or recombine one with another. The contribution of each of these processes depends on the distribution of electric potential along the ion chain.

The calculations were made as follows: $n$ stands for the number of host ions contained in the ion chain. The chain length is $l=n a$, where $a$ is the parameter of the ion chain. The mean distance between impurities in the crystal lattice is determined by their concentration. Impurity ions concentration varied from 0.01 to $0.5 \mathrm{~mol} \%$.

The calculations of radiation sensitivity of the fluorite crystals under initial irradiation at $80 \mathrm{~K}$ were conducted as follows. Irradiation generates an electron-hole pair: in the ion chain, there are $N=n^{2}$ ways of arrangement of the electron vs. the hole. Each of them was taken into account at calculation of the electron-hole pair relaxation. The electron-hole pairs can localize: (a) on the impurityvacancy dipoles thereby forming a complementary pair of color centers $\left(n_{1}\right)$; (b) on the same IVD $\left(n_{2}\right)$; (c) on the electron-hole pair relaxation on one of the nodes of the ion chain $\left(n_{3}\right)$. At this $n_{1}+n_{2}+n_{3}=N$. Having found $n_{1}, n_{2}$, and $n_{3}$, one can calculate the probability of color centers generation $\left(\omega_{1}\right)$ and of their radiation decay $\left(\omega_{2}\right)$ :

$$
\omega_{1}=\frac{n_{1}}{N} ; \quad \omega_{2}=\frac{n_{2}}{N} .
$$

At the stage of the crystal coloration saturation the dy- namic equilibrium is achieved between color centers generation processes and bleaching effect of the radiation. The calculation data is adduced in Tables I-III. Table I presents the results of calculations of parameters describing the radiation sensitivity of the $\mathrm{CaF}_{2} \mathrm{O}^{2-}$ crystals. Probability of color centers generation $\left(\omega_{1}, \omega_{4}\right)$ and of their radiation decay $\left(\omega_{2}, \omega_{3}\right.$ and $\left.\omega_{5}\right)$ during the disintegration of the electron-hole pair in the ion chain fragment; $[c]$ - molar concentration of the oxygen in the crystal lattice; $l$ - average distance between impurity ions; $a$ - parameter of the lattice; $\left[c_{D}\right]_{0}-$ dipole pairs concentration in the crystal lattice before its irradiation: $\left[c_{D}\right]_{0}=\frac{1}{2}[c] ;[c]_{1}$ and $\left[c_{D}\right]_{1}$ - concentration of pairs of color centers and of IVD-pairs after low-temperature irradiation of the samples $(=80 \mathrm{~K})$ at the stage of color saturation of the crystal; $[c]_{2}$ and $\left[\mathrm{c}_{D}\right]_{2}-$ concentration of pairs of color centers and of IVD-pairs after the irradiation of the samples at $>150 \mathrm{~K}$ at the stage of color saturation of the crystal.

TABLE I

Parameters of the radiation sensitivity of $\mathrm{CaF}_{2}-\mathrm{O}^{2-}$ (for notations see the text).

\begin{tabular}{c|c|c|c|c|c|c|c|c|c}
\hline \hline$c$ & $l$ & $\omega_{1}$ & $\omega_{2}$ & $\omega_{3}$ & $c_{1}: c_{0}$ & $n_{1}\left[\mathrm{~cm}^{-3}\right]$ & $c_{2}: c_{0}$ & $n_{2}\left[\mathrm{~cm}^{-3}\right]$ & $c_{2}: c_{1}$ \\
\hline 0.50 & 6 & 0.100 & 0.32 & 0.067 & 0.240 & $6 \times 10^{18}$ & 0.60 & $1.5 \times 10^{19}$ & 2.5 \\
0.10 & 10 & 0.069 & 0.32 & 0.044 & 0.180 & $9 \times 10^{17}$ & 0.61 & $3.1 \times 10^{18}$ & 3.4 \\
0.01 & 21 & 0.032 & 0.33 & 0.014 & 0.088 & $4.4 \times 10^{16}$ & 0.70 & $3.5 \times 10^{17}$ & 8.0
\end{tabular}

TABLE II

Limit concentrations of color centers after re-irradiation (subscript index 2) of the discolored crystal at $T_{2}=80 \mathrm{~K}$ (initial irradiation at $T_{1}=80 \mathrm{~K}$ ). $\left[\mathrm{M}_{A}^{+}\right]_{1}$ is a limit concentration of $\mathrm{M}_{A}^{+}$-centers after initial irradiation of the crystal.

\begin{tabular}{c|c|c|c|c|c|c}
\hline \hline$[c][\mathrm{mol} . \%]$ & $l$ & $\frac{\left[\mathrm{F}_{D}\right]_{2}}{\left[c_{D}\right]_{0}}$ & $\frac{\left[\mathrm{F}_{A}\right]_{2}}{\left[c_{D}\right]_{0}}$ & $\frac{\left[M_{A}^{+}\right]_{2}}{\left[c_{D}\right]_{0}}$ & $\frac{\left[\mathrm{F}_{A}\right]_{2}}{\left[M_{A}^{+}\right]_{2}}$ & $\frac{\left[M_{A}^{+}\right]_{2}}{\left[M_{A}^{+}\right]_{1}}$ \\
\hline 0.50 & 6 & 0.19 & 0.18 & 0.37 & 0.51 & 1.5 \\
0.10 & 10 & 0.15 & 0.14 & 0.29 & 0.52 & 1.7 \\
0.01 & 21 & 0.086 & 0.081 & 0.17 & 0.51 & 1.8
\end{tabular}

TABLE III

Limit concentrations of color centers in $\mathrm{CaF}_{2}-\mathrm{O}^{2-}$ crystal that emerged under its re-irradiation $\left(T_{1}=250 \mathrm{~K}, T_{2}=\right.$ $80 \mathrm{~K})$.

\begin{tabular}{c|c|c|c|c|c|c}
\hline \hline$[c][\mathrm{mol} . \%]$ & $l$ & $\frac{\left[\mathrm{F}_{D}\right]_{2}}{\left[c_{D}\right]_{0}}$ & $\frac{\left[\mathrm{F}_{A}\right]_{2}}{\left[c_{D}\right]_{0}}$ & $\frac{\left[M_{A}^{+}\right]_{2}}{\left[c_{D}\right]_{0}}$ & $\frac{\left[\mathrm{F}_{A}\right]_{2}}{\left[M_{A}^{+}\right]_{2}}$ & $\frac{\left[M_{A}^{+}\right]_{2}}{\left[M_{A}^{+}\right]_{1}}$ \\
\hline 0.50 & 6 & 0.46 & 0.100 & 0.56 & 0.82 & 0.97 \\
\hline 0.10 & 10 & 0.55 & 0.065 & 0.62 & 0.89 & 0.99 \\
\hline 0.01 & 21 & 0.67 & 0.027 & 0.70 & 0.96 & 1.00
\end{tabular}

Limit concentrations of color centers were computed by the following formulae:

$$
\begin{array}{ll}
c_{1}=\frac{\omega_{1}}{\omega_{1}+\omega_{2}} c_{0} ; \quad n_{1}=\frac{\omega_{1}}{\omega_{1}+\omega_{2}} n_{0}, \\
c_{2}=\frac{\omega_{1}}{\omega_{1}+\omega_{3}} c_{0} ; \quad n_{2}=\frac{\omega_{1}}{\omega_{1}+\omega_{3}} n_{0},
\end{array}
$$

where $n_{0}$ is the IVD-pairs concentration in the crystal before the irradiation. 


$$
\begin{aligned}
& {\left[\mathrm{F}_{A}\right]_{2}=\frac{\omega_{1}}{\omega_{1}+\omega_{2}} ; \quad\left[c_{D}\right]=\frac{\omega_{1} \omega_{2}}{\left(\omega_{1}+\omega_{2}\right)^{2}}\left[c_{D}\right]_{0} ;} \\
& {\left[\mathrm{F}_{D}\right]_{2}=\frac{\omega_{2}}{\omega_{1}+\omega_{2}}\left[c_{D}\right]_{1}=} \\
& \quad \frac{\omega_{1} \omega_{2}}{\left(\omega_{1}+\omega_{2}\right)\left(\omega_{1}+\omega_{2}\right)}\left[c_{D}\right] ; \\
& {\left[M_{A}^{+}\right]_{2}=\left[F_{D}\right]_{2}+\left[\mathrm{F}_{A}\right]_{2} ; \quad\left[M_{A}^{+}\right]_{1}=[c]_{1} ;} \\
& {\left[\mathrm{F}_{A}\right]_{2}=\frac{\omega_{1}}{\omega_{1}+\omega_{2}}\left[c_{D}\right]_{2}=} \\
& \quad \frac{\omega_{1} \omega_{3}}{\left(\omega_{1}+\omega_{2}\right)\left(\omega_{1}+\omega_{3}\right)}\left[c_{D}\right]_{0} ; \\
& {\left[\mathrm{F}_{D}\right]_{2}=\frac{\omega_{4}}{\omega_{4}+\omega_{5}}\left[c_{D}\right]_{2}=} \\
& \quad \frac{\omega_{3} \omega_{4}}{\left(\omega_{4}+\omega_{5}\right)\left(\omega_{1}+\omega_{3}\right)}\left[c_{D}\right] ; \\
& {\left[M_{A}^{+}\right]_{2}=\left[F_{D}\right]_{2}+\left[\mathrm{F}_{A}\right]_{2} ; \quad\left[M_{A}^{+}\right]_{1}=[c]_{2} ;}
\end{aligned}
$$

\section{Discussion}

As data in Table I data suggests, under lowtemperature irradiation of the crystal the probability $\omega_{1}$ of color centers generation is less than the probability $\omega_{2}$ of their radiation bleaching. Accordingly, color center concentration is considerably lower than the IVD concentration. Conversely, if the crystal is being irradiated at room temperature, $\omega_{1}$ is higher than $\omega_{3}$. Consequently, at the crystal coloration saturation the concentration of color centers exceeds the IVD concentration. As the bleaching effect of the ionizing radiation dominates at lower temperatures than at room temperatures $\left(\omega_{2}>\omega_{3}\right)$ this factor significantly enhances the radiation sensitivity (the ability for coloration) of the crystals with the increase of the temperature of irradiation.

Let us compare the radiation sensitivity of the doped fluorite crystals with that of alkali halide crystals, in particular, with well-studied in the literature $\mathrm{KCl}$ crystal [3]. According to literary source, the limit concentration of color centers in $\mathrm{KCl}$ crystals is about $10^{18} \mathrm{~cm}^{-3}$. As Table I demonstrates, this is exactly the radiation sensitivity of the fluorite crystals at the oxygen concentration of $0.1 \mathrm{~mol} \%$. As the oxygen content reaches $0.5 \mathrm{~mol} . \%$, the color centers concentration runs up to $10^{19} \mathrm{~cm}^{-3}$ which is by order of magnitude higher than that in $\mathrm{KCl}$ crystals [3].

\section{Conclusions}

In the re-irradiated crystals (Tables I-III), the limit concentration of color centers is 3-8 times higher than the concentration of color centers being generated by the initial irradiation of the crystal, which is also confirmed experimentally. Therefore, by performing the following sequence of actions: irradiation of $\mathrm{MeF}_{2}-\mathrm{O}^{2-}$ crystals at nitrogen temperatures - warming-up to room temperatures - cooling-down to liquid nitrogen temperatures bleaching at nitrogen temperatures - re-irradiation at nitrogen temperatures, one can repeatedly increase the color centers concentration. In this way, one can amplify the radiation sensitivity of the oxygen-doped fluorite crystals. Increasing the radiation sensitivity of modified oxygen-containing fluorite crystals will improve the operational properties of devices operating on their basis.

\section{References}

[1] Crystals with the Fluorite Structure: Electronic, Vibrational, and Defect Properties, Ed. W. Hayes, Oxford University Press, Oxford 1974.

[2] Z.P. Chornij, I.M. Kravchuk, S.I. Kachan, G.O. Shchur, V.M. Salapak, Phys. Status Solidi B 223, 757 (2001).

[3] E.M. Olimpios, Radiat. Eff. 14, 119 (1972).

[4] P.W.M. Jacobs, S.H. Ong, A.V. Chadwick, V.M. Carr, J. Solid State Chem. 33, 159 (1980).

[5] W. Bollman, Phys. Status Solidi A 60, 661 (1980).

[6] S.I. Kachan, E.E. Obukhova, V.F. Shtanko, E.P. Chinkov, Acta Phys. Pol. A 117, 195 (2010). 